\title{
Lymph node metastasis and the physicochemical micro- environment of pancreatic ductal adenocarcinoma xenografts
}

\author{
Lise Mari K. Andersen ${ }^{1}$, Catherine S. Wegner ${ }^{1}$, Trude G. Simonsen ${ }^{1}$, Ruixia Huang ${ }^{1}$, \\ Jon-Vidar Gaustad ${ }^{1}$, Anette Hauge ${ }^{1}$, Kanthi Galappathi ${ }^{1}$ and Einar K. Rofstad ${ }^{1}$ \\ ${ }^{1}$ Group of Radiation Biology and Tumor Physiology, Department of Radiation Biology, Institute for Cancer Research, Oslo \\ University Hospital, Oslo, Norway \\ Correspondence to: Einar K. Rofstad, email: einar.k.rofstad@rr-research.no \\ Keywords: pancreatic carcinoma, metastasis, angiogenesis, hypoxia, interstitial fluid pressure \\ Received: December 02, $2016 \quad$ Accepted: May 01, $2017 \quad$ Published: May 26, 2017 \\ Copyright: Andersen et al. This is an open-access article distributed under the terms of the Creative Commons Attribution License \\ 3.0 (CC BY 3.0), which permits unrestricted use, distribution, and reproduction in any medium, provided the original author and \\ source are credited.
}

\section{ABSTRACT}

Pancreatic ductal adenocarcinoma (PDAC) patients develop lymph node metastases early and have a particularly poor prognosis. The poor prognosis has been shown to be associated with the physicochemical microenvironment of the tumor tissue, which is characterized by desmoplasia, abnormal microvasculature, extensive hypoxia, and highly elevated interstitial fluid pressure (IFP). In this study, we searched for associations between lymph node metastasis and features of the physicochemical microenvironment in an attempt to identify mechanisms leading to metastatic dissemination and growth. BxPC-3 and Capan-2 PDAC xenografts were used as preclinical models of human PDAC. In both models, lymph node metastasis was associated with high IFP rather than high fraction of hypoxic tissue or high microvascular density. Seven angiogenesis-related genes associated with high IFPassociated lymph node metastasis were detected by quantitative PCR in each of the models, and these genes were all up-regulated in high IFP/highly metastatic tumors. Three genes were mutual for the BxPC-3 and Capan-2 models: transforming growth factor beta, angiogenin, and insulin-like growth factor 1. Further comprehensive studies are needed to determine whether there is a causal relationship between the up-regulation of these genes and high IFP and/or high propensity for lymph node metastasis in PDAC.

\section{INTRODUCTION}

Pancreatic ductal adenocarcinoma (PDAC) is the fourth leading cause of cancer-related deaths in the United States with a 5-year survival rate of 5-7\% [1,2], and unlike many other types of cancer, the incidence of PDAC is increasing [3]. Because most PDACs are resistant to chemotherapy and radiation treatment [4], surgery is the only treatment modality that may result in cure [5]. However, only $10-20 \%$ of the patients are eligible for surgery at presentation, and even then, the outcome is poor with a 5 -year survival rate of $15-20 \%$ $[6,7]$. Metastatic spread into and through lymphatics and lymph nodes occurs frequently in PDAC patients, and the presence of lymph node metastases is strongly associated with poor prognosis [8]. Ultimately, most patients die from metastatic disease in the liver, lungs, or peritoneum [9].

The microenvironment of PDACs is characterized by an abundant desmoplastic stroma that may occupy up to $80 \%$ of the tumor volume [10-12]. The PDAC stroma consists of a dynamic assortment of extracellular matrix components including fibronectin, collagen, proteoglycans, and hyaluronic acid, nonmalignant cells including fibroblasts, endothelial cells, and immune cells, and soluble proteins such as growth factors and cytokines [12]. Recent investigations have revealed that the PDAC stroma represents a physical barrier to the delivery of chemotherapeutic agents and simultaneously supports 
tumor growth and promotes metastatic dissemination [10-12].

The development of an abundant stroma during tumor growth distorts the architecture of the normal pancreas, resulting in an abnormal configuration of blood vessels and lymphatics in PDACs $[13,14]$. Histological examinations of tumors in genetically engineered mouse models of PDAC and human PDACs have revealed that PDACs are hypovascular $[15,16]$. Thus, the microvascular density (MVD) has been measured to be significantly lower in PDACs than in the normal pancreas, and furthermore, it has been shown that PDACs have significantly fewer large-diameter blood vessels (diameter $>10 \mu \mathrm{m})$ than the adjacent non-tumorigenic pancreatic tissue [17-21]. The paucity of large-diameter vessels is believed to be a consequence of vessel compression induced by water retention in the hyaluronan component of the tumor stroma [21-24]. The geometric resistance to blood flow is high in microvascular networks showing high fractions of low-diameter vessels, resulting in elevated microvascular pressure and low erythrocyte velocities [25]. Tumors with low MVD and high fractions of low-diameter vessels may develop interstitial hypertension and hypoxic regions during growth [26, 27], and indeed, preclinical and clinical investigations have revealed that PDACs may show highly elevated interstitial fluid pressure (IFP) $[21,28,29]$ as well as high fractions of hypoxic tissue [30-36].

The dense desmoplastic stroma has been suggested to be a determinant of the aggressive metastatic growth of PDACs [10-12]. There is some evidence that PDAC metastasis is promoted by direct interactions between the parenchymal tumor cells and the cellular and/or matrix components of the stroma [37, 38]. Because studies of a large number of cancer types have revealed that metastasis is associated with several parameters of the physicochemical microenvironment of the tumor tissue, including MVD [39, 40], IFP [41, 42], and extent of hypoxia [43-45], it is possible that also the metastatic propensity of PDACs is determined by these parameters. This possibility was investigated in the present work by using intramuscular BxPC-3 and Capan-2 PDAC xenografts as preclinical tumor models. Tumors were subjected to measurement of IFP when having grown to an appropriate size, and then the tumors were resected and prepared for immunohistochemical assessment of MVD and hypoxic fraction, and the host mice were examined for the presence of lymph node metastases.

\section{RESULTS}

\section{Metastasis assay}

Intramuscular tumors were initiated in the left hind leg, and the metastatic status of the host mice was assessed by examining the popliteal lymph nodes (PLN), inguinal lymph nodes (ILN), proper axillary lymph nodes (PALN), accessory axillary lymph nodes (AALN), medial iliac lymph nodes (MILN), and renal lymph nodes (RLN; Figure 1A). These lymph nodes differed in size in mice without tumors, and the size of a given lymph node differed among individual mice (Figure 1B). In tumor-bearing mice, lymph nodes with lengths above those indicated by the horizontal lines in Figure 1B were considered to be metastatic, that is, lymph nodes longer than $2.8 \mathrm{~mm}$ (PLN), $4.2 \mathrm{~mm}$ (ILN), $6.0 \mathrm{~mm}$ (PALN), $4.8 \mathrm{~mm}$ (AALN), $3.7 \mathrm{~mm}$ (MILN), and $3.6 \mathrm{~mm}$ (RLN). Histological examinations confirmed that lymph nodes with lengths above these threshold values always contained pancreatic tumor cells. In general, a metastatic lymph node was substantially larger than the corresponding non-metastatic lymph node (Figure 1C), reflecting that most metastatic lymph nodes were pervaded by malignant tissue (Figure 1D).

\section{Tumor histology}

The histological appearance of the tumor models is illustrated in Figure 2. Both models were differentiated and showed ductal structures; however, the level of differentiation was higher in Capan-2 tumors than in BxPC-3 tumors (Figure 2A). CD31 was used as a marker of endothelial cells, and histological preparations stained for CD31 showed that the blood vessels in both models were located primarily in the connective tissue rather than in the tumor parenchyma (Figure 2B). Pimonidazole was used as a marker of tumor hypoxia, and both models showed foci of pimonidazole-positive cells in morphologically intact tissue, and positive pimonidazole staining was always seen in tissue adjacent to necrotic and fibrotic tumor regions (Figure 3).

\section{Physicochemical tumor microenvironment and lymph node metastasis}

Associations between lymph node metastasis and the physicochemical microenvironment of tumors were searched for by measuring IFP, hypoxic fraction $\left(\mathrm{HF}_{\mathrm{Pim}}\right)$, and MVD in 20 tumors of each model and relating the measured values to the metastatic status of the host mice. The physicochemical microenvironment differed substantially among the individual tumors in both models (Figure 4). IFP ranged from $8.9 \mathrm{mmHg}$ to $47.5 \mathrm{mmHg}$ (BxPC-3) and from $4.6 \mathrm{mmHg}$ to $49.3 \mathrm{mmHg}$ (Capan-2), $\mathrm{HF}_{\mathrm{Pim}}$ ranged from $2.2 \%$ to $15.9 \%(\mathrm{BxPC}-3)$ and from $2.6 \%$ to $38.8 \%$ (Capan-2), and MVD $\left(\# / \mathrm{mm}^{2}\right)$ ranged from 88 to 226 (BxPC-3) and from 93 to 163 (Capan-2). IFP did not correlate with $\mathrm{HF}_{\text {Pim }}$ or MVD in any of the models, whereas $\mathrm{HF}_{\text {Pim }}$ decreased with increasing MVD in the BxPC-3 model $\left(P<0.0001 ; R^{2}=0.56\right)$, but not in the Capan-2 model $(P>0.05)$.

Metastasis to the liver, lungs, or peritoneum was not detected in any of the 40 mice included in the study. Thirty-seven mice had developed metastatic growth in 
one or more lymph nodes, implying that only three mice (two with BxPC-3 tumors and one with a Capan-2 tumor) were metastasis-free. It is possible that also these three mice would have developed lymph node metastases if the primary tumor had been allowed to grow beyond a size of $600 \mathrm{~mm}^{3}$. Ten of the 20 mice with BxPC-3 tumors showed two or more metastasis-positive lymph nodes ( $n>$ 1) whereas the other 10 mice showed none or one lymph node with metastatic growth $(n<2$; Figure 5$)$. The more metastatic tumors had significantly higher IFP than the less metastatic tumors $(P=0.0018)$, whereas these two tumor groups did not differ significantly in $\mathrm{HF}_{\text {Pim }}(P>$ $0.05)$ or MVD $(P>0.05)$. Of the 20 mice with Capan-2 tumors, four mice showed none or one lymph node with metastatic growth $(n<2), 12$ mice had developed two metastasis-positive lymph nodes $(n=2)$, and four mice showed three or more lymph nodes with metastases $(n>$ 2; Figure 5). These three groups did not differ significantly in $\mathrm{HF}_{\text {Pim }}(P>0.05)$ or MVD $(P>0.05)$. However, oneway ANOVA followed by the Bonferroni's test revealed that the IFP was significantly higher in the $(n>2)$-group than in the $(n<2)$-group $(P=0.012)$, whereas there was no significant difference in IFP between the $(n=2)$-group and the $(n<2)$-group $(P>0.05)$ or the $(n>2)$-group $(P$ $>0.05)$. Furthermore, the Student $t$ test showed that the IFP of the 16 tumors giving rise to two or more than two lymph nodes with metastases was significantly higher than the IFP of the four tumors giving rise to none or
A

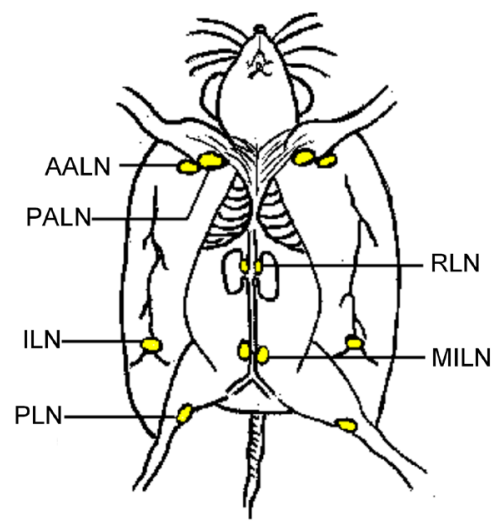

C

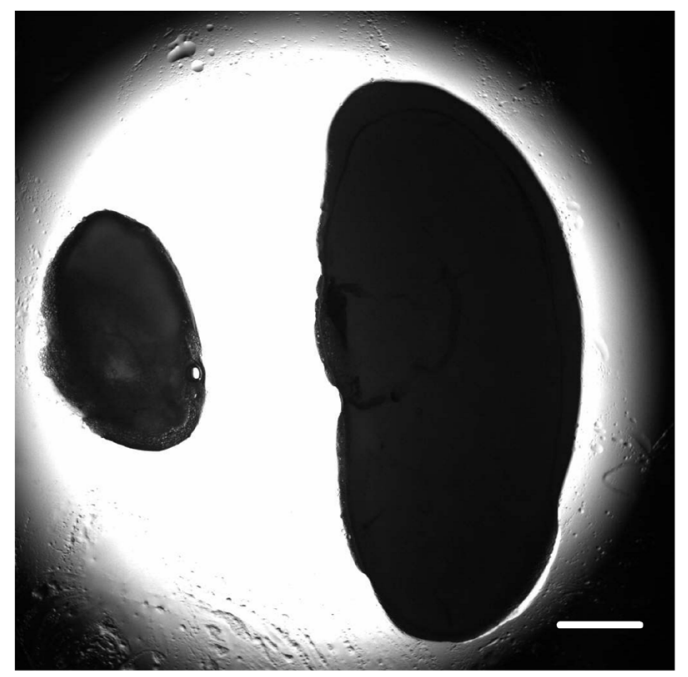

B

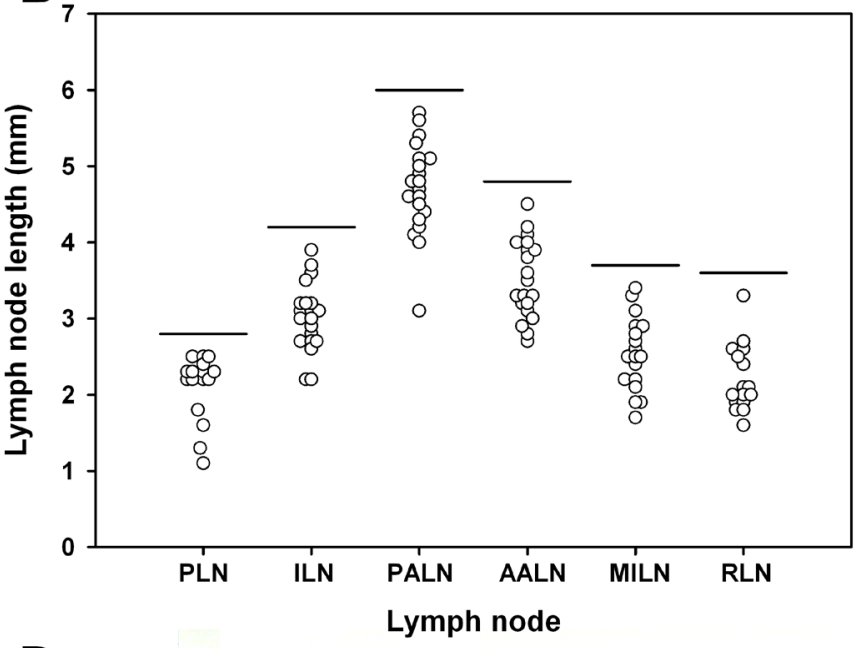

D

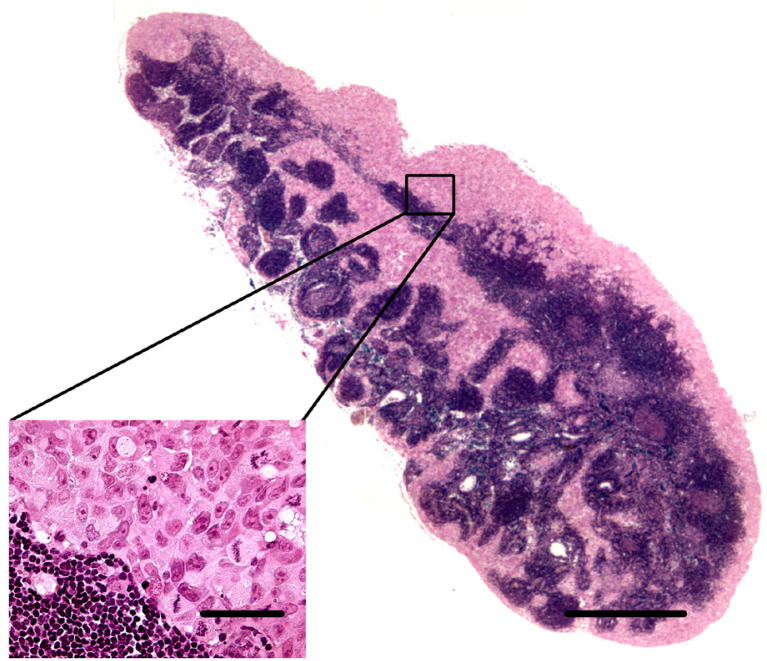

Figure 1: Metastasis assay. (A) Six pairs of lymph nodes were examined for metastatic growth: PLN, popliteal lymph nodes; ILN, inguinal lymph nodes; PALN, proper axillary lymph nodes; AALN, accessory axillary lymph nodes; MILN, medial iliac lymph nodes; RLN, renal lymph nodes. (B) Length of these lymph nodes in mice without tumors. The horizontal lines indicate the threshold lymph node lengths, that is, lymph nodes with lengths above the threshold values were considered to show metastatic growth. The threshold values are $2.8 \mathrm{~mm}$ (PLN), $4.2 \mathrm{~mm}$ (ILN), $6.0 \mathrm{~mm}$ (PALN), $4.8 \mathrm{~mm}$ (AALN), $3.7 \mathrm{~mm}$ (MILN), and $3.6 \mathrm{~mm}$ (RLN). (C) Representative examples of lymph nodes without (left) and with (right) metastatic growth. Scale bar: $1.0 \mathrm{~mm}$. (D) Histological section prepared from a representative lymph node with metastatic growth. Scale bars: $100 \mu \mathrm{m}$ (high magnification) and $1.0 \mathrm{~mm}$ (low magnification). 
one metastasis-positive lymph node $(P=0.035)$. Taken together, these data suggest that the metastatic propensity of the BxPC-3 and Capan-2 tumors was associated with high IFP, but not with high $\mathrm{HF}_{\text {Pim }}$ or MVD.

\section{Angiogenesis-related genes associated with interstitial hypertension-associated lymph node metastasis}

To identify genes associated with interstitial hypertension-associated lymph node metastasis, quantitative PCR was carried out on highly metastatic primary tumors $(n=2)$ with high IFP (IFP $>40 \mathrm{mmHg}$ ) and poorly metastatic primary tumors $(n<2)$ with low IFP (IFP $<25 \mathrm{mmHg}$ ) by using a PCR array for expression profiling of angiogenesis-related genes. Four tumors of each category were examined in both models. In the BxPC3 model, we identified seven genes that were significantly up-regulated in the high IFP/highly metastatic tumors and showed a mean expression level in these tumors that was $>2$-fold higher than that in the low IFP/poorly metastatic tumors (Figure 6). Vascular endothelial growth factor-C (VEGF-C) was by far the angiogenesis-related gene that showed the largest difference in expression level between high IFP/highly metastatic tumors and low IFP/poorly metastatic tumors in the BxPC-3 model. By the same criteria, seven angiogenesis-related genes associated with interstitial hypertension-associated metastasis were also identified in the Capan-2 model (Figure 6). In this model, the largest differences in expression level between high IFP/highly metastatic tumors and low IFP/poorly metastatic tumors were seen for chemokine (C-X-C motif) ligand 5 (CXCL5) and tumor necrosis factor (TNF). The BxPC-3 and Capan-2 models had three angiogenesisrelated genes in common that were associated with interstitial hypertension-associated metastasis: angiogenin (ANG), insulin-like growth factor-1 (IGF1), and transforming growth factor beta (TGFB).

\section{BXPC-3}

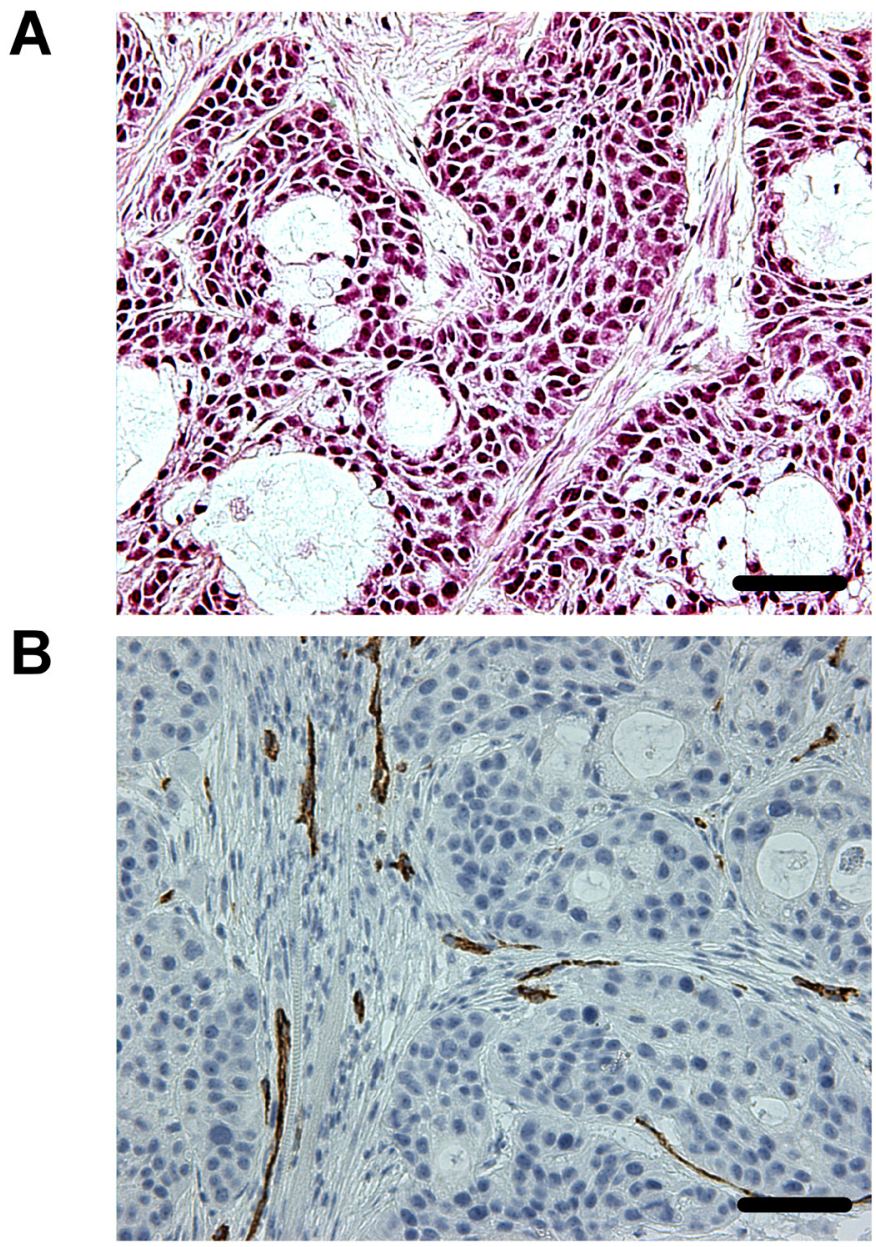

\section{Capan-2}
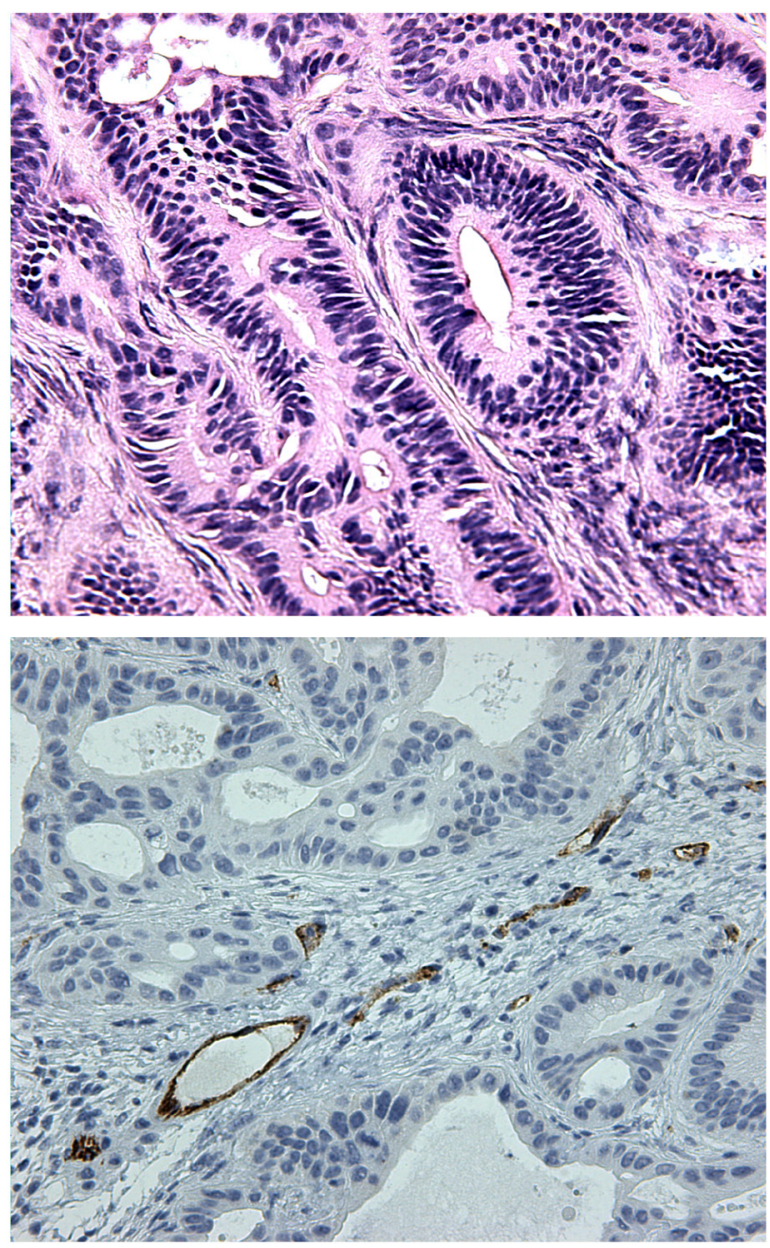

Figure 2: Histological appearance of BxPC-3 and Capan-2 PDAC xenografts. (A) HE stained preparations. Scale bar: 500 $\mu \mathrm{m}$. (B) Immunohistochemical preparations stained for blood vessels by using an antibody against the endothelial cell marker CD31. Scale bar: $500 \mu \mathrm{m}$. 


\section{Tumor-associated lymphatics and lymph node metastasis}

Lymph node metastasis in human PDAC has been shown to be associated with high expression of VEGF-C and high density of lymphatics [8], and because high IFP/ highly metastatic BxPC-3 tumors showed highly elevated expression of VEGF-C, we examined the presence of tumor-associated lymphatics in high IFP/highly metastatic and low IFP/poorly metastatic tumors by using an immunohistochemical assay and LYVE-1 as a marker of lymphatic endothelial cells. Positive intratumoral staining for LYVE-1 could not be detected in either of the PDAC models (Figure 7A and 7B), whereas the peritumoral muscle tissue of both models showed LYVE1-positive lymphatics (Figure 7C). In the BxPC-3 model, the density of peritumoral lymphatics was significantly higher in high IFP/highly metastatic tumors than in low IFP/poorly metastatic tumors $(P=0.0011)$, whereas in the Capan-2 model, high IFP/highly metastatic and low IFP/

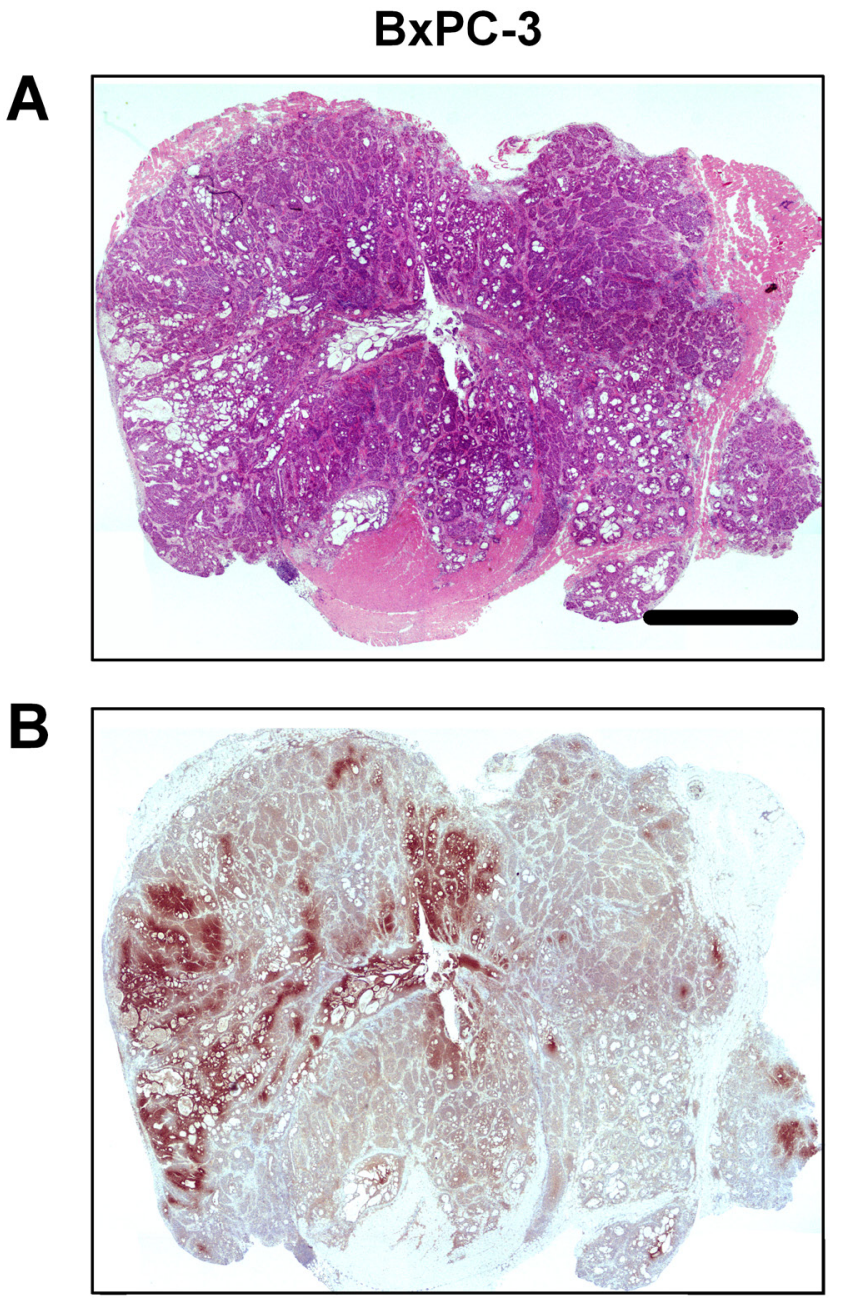

poorly metastatic tumors did not differ significantly in peritumoral lymph vessel density (Figure 7D), consistent with the VEGF-C expression data in Figure 6.

\section{DISCUSSION}

Preclinical studies of PDAC are currently being carried out by using a wide variety of tumor models, including transgenic mouse models, ectopic or orthotopic patient-derived xenograft models, and cell line-derived xenograft models transplanted to subcutaneous or intramuscular sites. Transgenic models have the advantage that the tumors arise spontaneously in the pancreas of immune-competent mice, whereas xenograft models have the advantage that the tumors consist of human malignant cells. In this study, intramuscular BxPC-3 and Capan-2 PDAC xenografts were used as models of human PDAC, and similar to other preclinical PDAC models, these models have some significant limitations. The intramuscular site is an ectopic site for PDAC, and
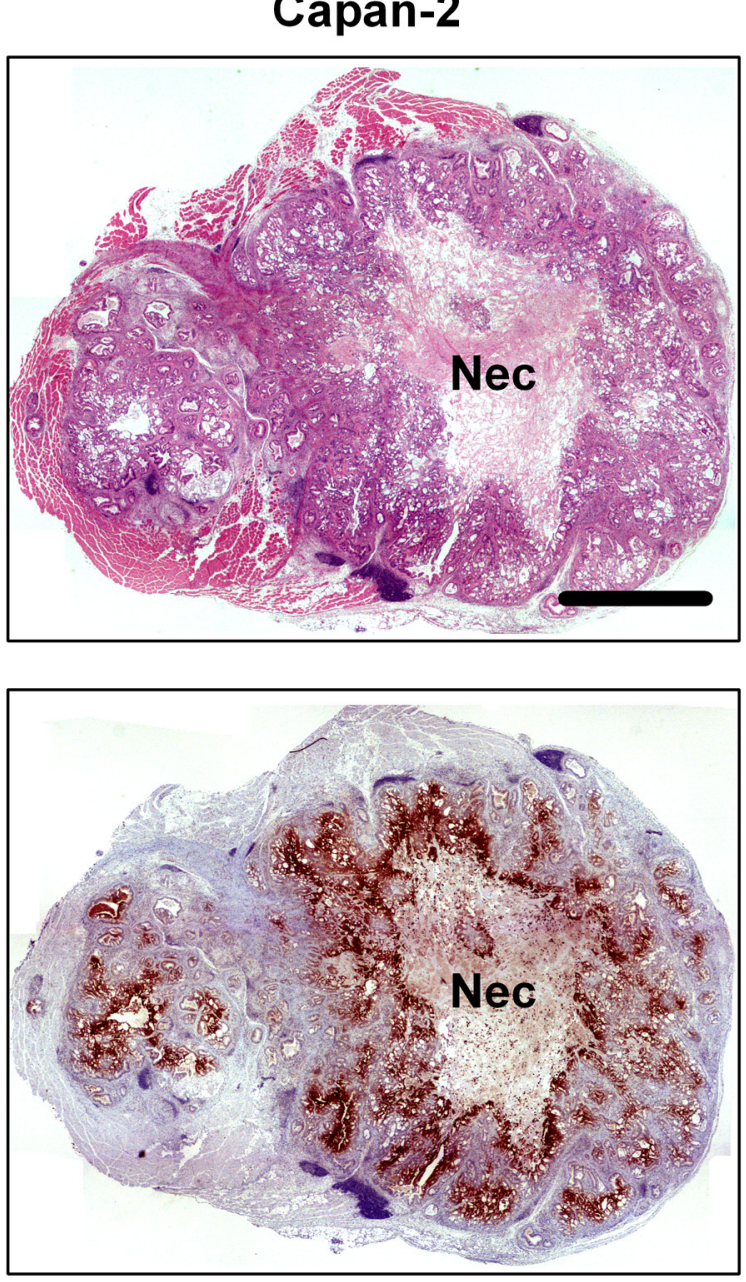

Figure 3: Whole mount histological preparations of BxPC-3 and Capan-2 PDAC xenografts. (A) HE stained preparations. Scale bar: $2.0 \mathrm{~mm}$. Nec: necrosis. (B) Immunohistochemical preparations stained for hypoxia by using an antibody against the hypoxia marker pimonidazole. Dark brown: hypoxic tissue. 
therefore, the tumor microenvironment of intramuscular PDAC xenografts cannot completely recapitulate the very complex desmoplastic tumor microenvironment of human PDACs [20, 28]. Lymph node metastasis of PDAC is promoted by direct interactions between the parenchymal tumor cells and the cellular and matrix components of the tumor stroma [37, 38], and consequently, the metastatic propensity of ectopic PDAC models may not necessarily be similar to that of PDACs in cancer patients. Furthermore, the incidence and the site of development of lymph node metastases depend on the density and structure of the peritumoral lymphatics [8, 13, 14], and the peritumoral lymphatic network of intramuscular PDAC xenografts may differ from that of human PDACs. Importantly, patients with PDAC primarily develop intra-abdominal lymph node metastases, and so did the intramuscular BxPC-3 and Capan-2 PDAC xenografts.

It is important to note that the histological appearance of the BxPC-3 and Capan-2 PDAC xenografts was similar to that of PDACs in humans. Both PDAC models showed distinct ductal structures enclosed by an abundant desmoplastic stroma. The stroma was seen as a dense matrix of connective tissue fibers appearing in thick filament bundles, and the majority of the blood vessels were located within these bundles. We have shown previously that the extracellular matrix of BxPC-3 and Capan-2 xenografts is rich in collagen I [46], consistent with the observation that collagen $\mathrm{I}$ is up-regulated in human PDAC [47].

There is significant evidence from studies of experimental tumors that tumor hypoxia, IFP, and other parameters of the physicochemical tumor microenvironment are strongly dependent on the site of tumor transplantation [26]. In this study, the physicochemical microenvironment differed considerably among the individual tumors of the BxPC-3 and Capan-2 PDAC models, and the numerical values of the microenvironmental parameters were similar to those reported for other preclinical models of PDAC and human PDACs. The MVD $\left(\# / \mathrm{mm}^{2}\right)$ ranged from 88 to 226 (BxPC-3) and from 93 to 163 (Capan-2), and these values are comparable to the range of 88-177 measured in an investigation of 52 PDAC patients [18]. Fraction of hypoxic tissue differed from $2.2 \%$ to $15.9 \%$ (BxPC-3) and from $2.6 \%$ to $38.8 \%$ (Capan-2), and these fractions are similar to those of $0-25 \%$ measured in a study of 16 orthotopic patient-derived PDAC xenograft models [36] and those of $0-26 \%$ measured in a study of 10 PDAC
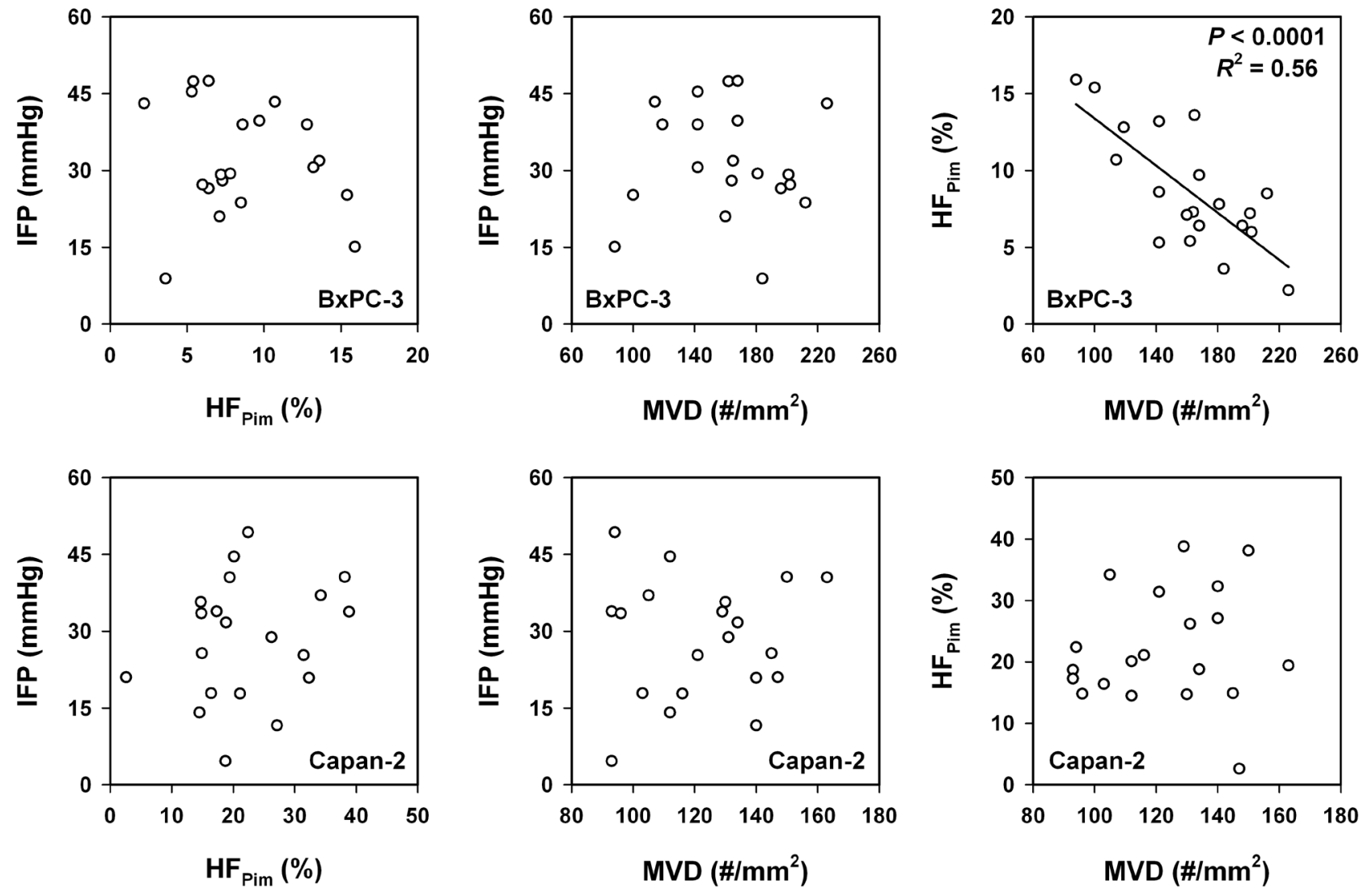

Figure 4: The physicochemical microenvironment of PDAC xenografts. Plots of interstitial fluid pressure (IFP) $v s$ hypoxic fraction $\left(\mathrm{HF}_{\mathrm{Pim}}\right)$, IFP vs microvascular density (MVD), and $\mathrm{HF}_{\mathrm{Pim}} v s \mathrm{MVD}$ for BxPC-3 and Capan-2 tumors. Symbols: individual tumors. Curve: linear regression line. 
patients [33, 34]. IFP varied from $8.9 \mathrm{mmHg}$ to 47.5 $\mathrm{mmHg}$ (BxPC-3) and from $4.6 \mathrm{mmHg}$ to $49.3 \mathrm{mmHg}$ (Capan-2), and these IFP values are within the same range as those measured in intramuscular tumor models of several cancer types [48] and in transgenic mouse models of PDAC [28]. Tumor IFP has also been measured in four treatment-naïve PDAC patients, and in that small study, IFP ranged from $6.1 \mathrm{mmHg}$ to $16.6 \mathrm{mmHg}$ [28].

Although MVD, $\mathrm{HF}_{\mathrm{Pim}}$, and IFP are parameters that are partly determined by the angiogenic activity of the tumor tissue, there were no correlations between these parameters with the only exception that $\mathrm{HF}_{\text {Pim }}$ decreased with increasing MVD in BxPC-3 tumors. The lack of correlation between $\mathrm{HF}_{\mathrm{Pim}}$ and MVD in Capan-2 tumors is not unexpected because it has been shown that many vessels in PDACs are occluded and hence nonfunctional due to mechanical pressure from the surrounding connective tissue $[20,21]$. The difference between the two PDAC models may be due to a higher fraction of nonfunctional vessels in Capan-2 tumors than in BxPC-3 tumors. Moreover, the observed absence of correlations between IFP and MVD or $\mathrm{HF}_{\mathrm{Pim}}$ is consistent with most previous studies, which showed a lack of correlation between the IFP of tumors and tumor vascularity or hypoxia, both in patients with cervix cancer [49] and in experimental tumors $[48,50,51]$.

Associations between lymph node metastasis and IFP, $\mathrm{HF}_{\text {Pim }}$, or MVD were searched for by comparing two groups of BxPC-3 tumors, one consisting of tumors giving rise to none or one positive lymph node and the other consisting of tumors giving rise to two or more positive lymph nodes, and three groups of Capan-2 tumors, one consisting of tumors metastasizing to none or one lymph node, one consisting of tumors metastasizing to two lymph nodes, and one consisting of tumors metastasizing to three of more lymph nodes. Ideally, the physicochemical microenvironment of tumors developing metastases should be compared with that of tumors that do not metastasize. However, this comparison was not appropriate because 18 of the $20 \mathrm{Bx}-\mathrm{PC}-3$ tumors and 19 of the 20 Capan-2 tumors

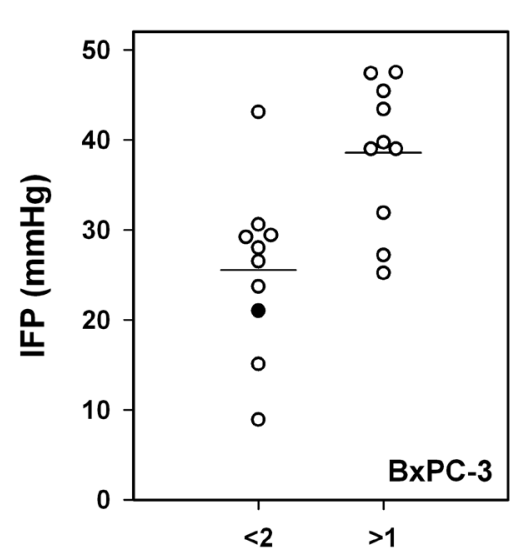

Metastases

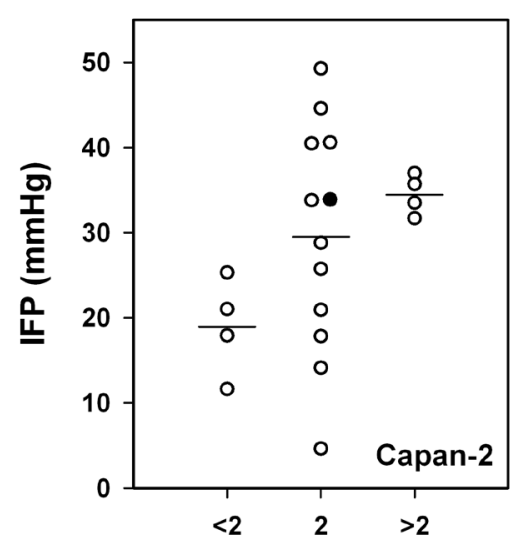

Metastases

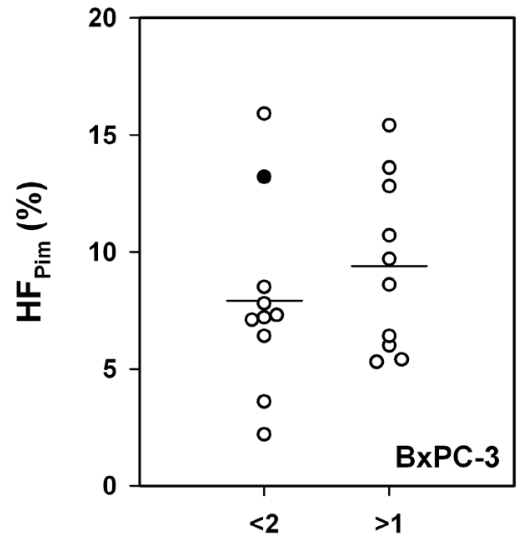

Metastases

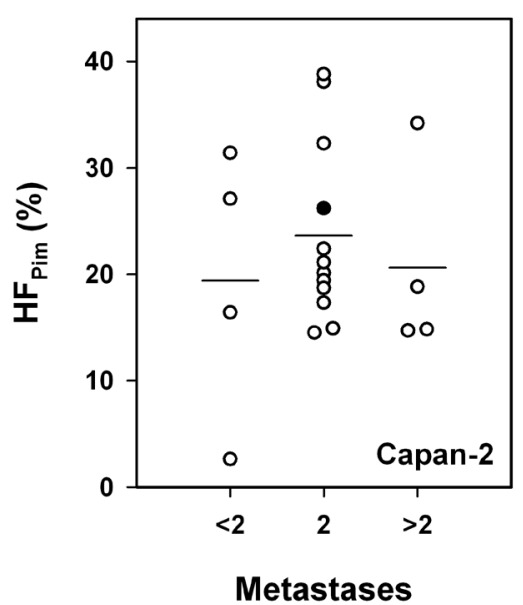

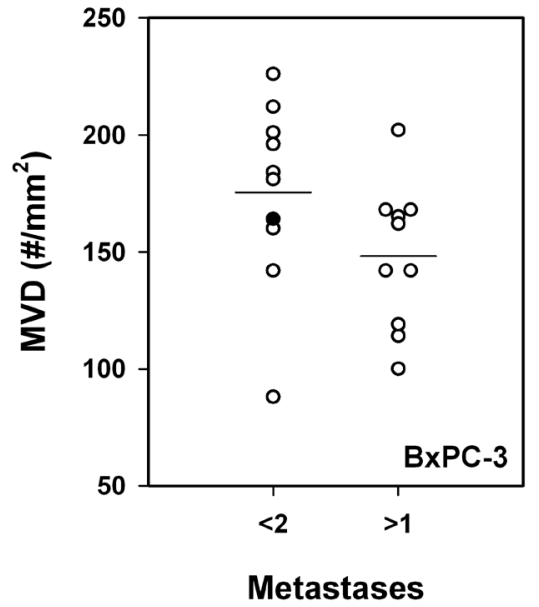

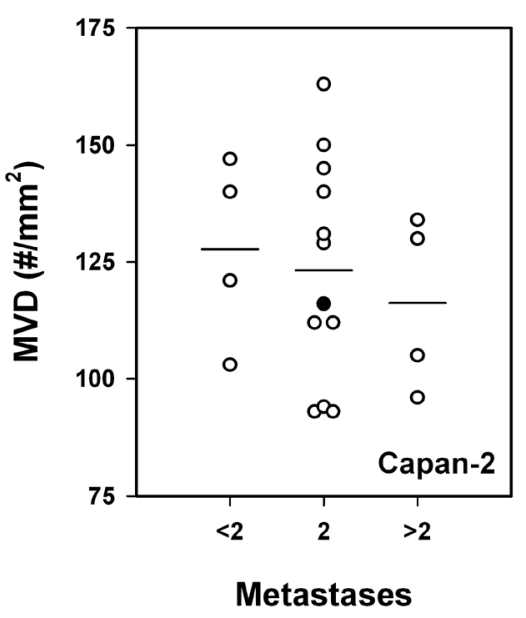

Figure 5: The metastatic propensity of PDAC xenografts. Interstitial fluid pressure (IFP), hypoxic fraction (HF ${ }_{\mathrm{Pim}}$ ), and microvascular density (MVD) in BxPC-3 tumors with low $(n<2)$ and high $(n>1)$ metastatic propensity and in Capan-2 tumors with low $(n<2)$, medium $(n=2)$, and high $(n>2)$ metastatic propensity. $n$ : number of lymph nodes showing metastatic growth. Symbols: individual tumors. Closed symbols: tumors depicted in Figure 3. Horizontal lines: mean values. 
metastasized to at least one lymph node. Our splitting of the BxPC-3 tumors resulted in two tumor groups of equal size (10 tumors in each group) and, hence, high power of the statistical analyses. Our division of the Capan-2 tumors resulted in three tumor groups of unequal sizes (4, 12 , and 4 tumors), and moreover, by using a splitting equal to that used for the BxPC-3 tumors, two groups of highly unequal sizes (4 and 16 tumors) were compared. Despite suboptimal divisions into tumor groups, IFP was found to be significantly different for the Capan-2 groups as it was for the BxPC-3 groups.
Lymph node metastasis was not associated with MVD or $\mathrm{HF}_{\text {Pim }}$ in either of the tumor models. The former observation contrasts with clinical studies of many tumor types, which have shown significant correlations between disease-free or overall survival rate and tumor microvascular density [39]. In these clinical studies, MVD was scored by counting vessels in vascular hot spots in the tumor periphery, whereas in our preclinical study, MVD was scored by counting vessels in whole tumor crosssections. Furthermore, there is significant evidence from clinical and preclinical investigations that extensive tumor
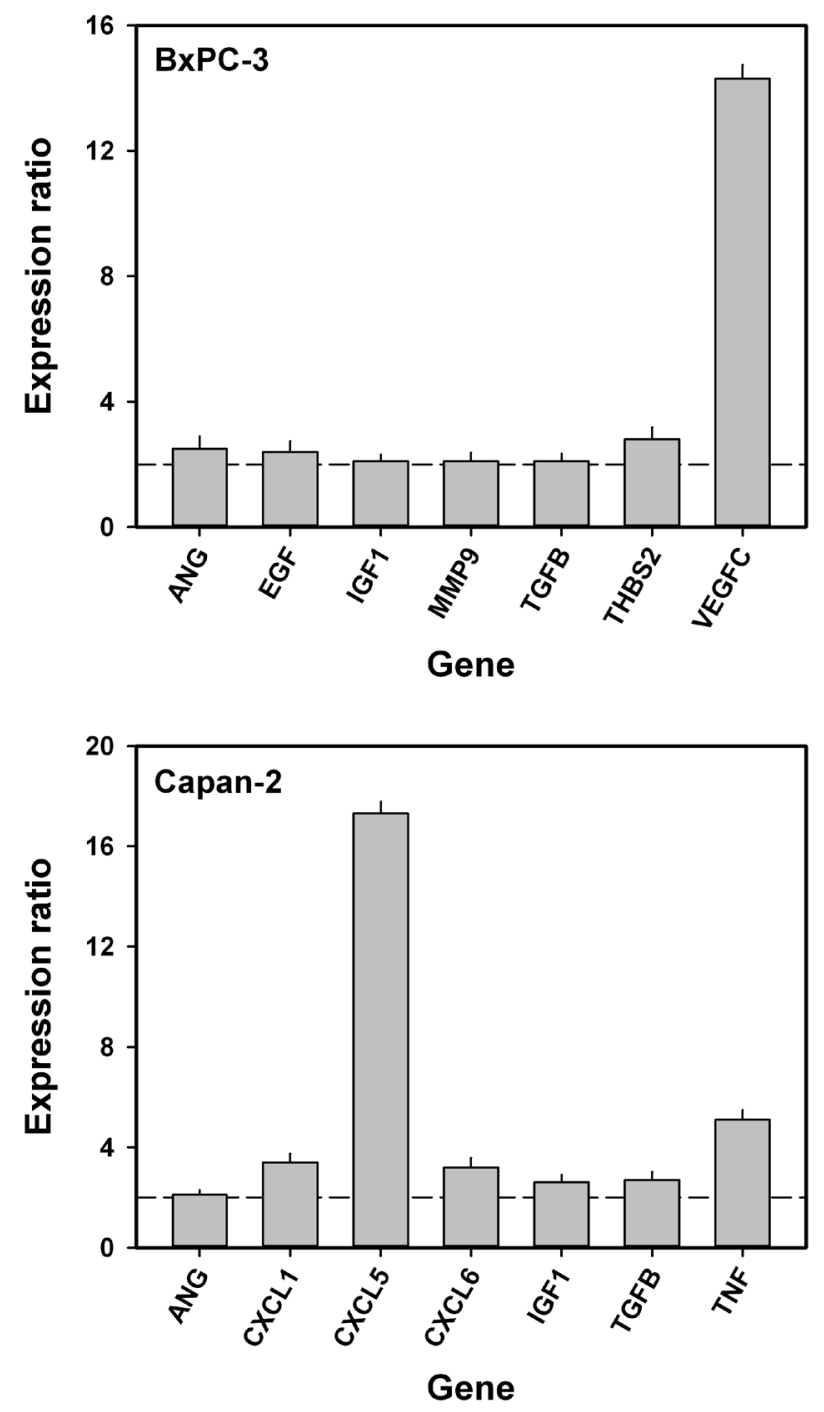

Figure 6: Angiogenesis-related genes associated with interstitial hypertension-associated lymph node metastasis in BxPC-3 and Capan-2 PDAC xenografts. Mean expression level in high IFP/highly metastatic tumors divided by mean expression level in low IFP/poorly metastatic tumors. Dashed horizontal lines indicate an expression ratio of 2 . The following genes were up-regulated in high IFP/highly metastatic BxPC-3 tumors: ANG, angiogenin $(P=0.023)$; EGF, epidermal growth factor $(P=0.030)$; IGF1, insulin-like growth factor $1(P=0.039)$; MMP9, matrix metallopeptidase $9(P=0.048)$; TGFB, transforming growth factor beta $(P=0.041)$; THBS2, thrombospondin $2(P=0.016)$; and VEGFC, vascular endothelial growth factor-C $(P<0.0001)$. The following genes were up-regulated in high IFP/highly metastatic Capan-2 tumors: ANG $(P=0.046)$; CXCL1, chemokine (C-X-C motif) ligand $1(P=0.010)$; CXCL5, chemokine (C-X-C motif) ligand $5(P<0.0001)$; CXCL6, chemokine $(\mathrm{C}-\mathrm{X}-\mathrm{C}$ motif) ligand $6(P=0.012)$; IGF1 $(P=0.027)$; TGFB $(P=$ $0.021)$; and TNF, tumor necrosis factor $(P=0.0025)$. ANG, IGF1, and TGFB were up-regulated in high IFP/highly metastatic tumors in both BxPC-3 and Capan-2 tumors. Columns and bars: mean values $\pm \mathrm{SD}$ ( $N=4$ tumors). 
hypoxia as well as high angiogenic activity may promote lymph node metastasis [26, 40, 43, 52, 53]. Similar studies of PDAC are sparse; however, there is some evidence from small clinical studies that tumor aggressiveness may be associated with high fraction of hypoxic tissue [33] or highly elevated angiogenesis [18] also in PDAC.

The present study suggests that lymph node metastasis in PDAC may be promoted primarily by interstitial hypertension rather than extensive tumor hypoxia or high angiogenic activity. The BxPC-3 and Capan-2 tumors did not develop intratumoral lymphatics, and our finding is consistent with studies of other tumors without functional intratumoral lymphatics. Thus, studies of melanoma and cervix carcinoma xenografts without intratumoral lymphatics have revealed that lymph node metastasis is associated with high IFP, both in tumors with and tumors without hypoxic regions [41, 42]. However, some patient-derived xenograft models of cervix carcinoma can develop functional intratumoral lymphatics, and functional intratumoral lymphatics may promote lymph node metastasis and reduce tumor IFP, leading to an inverse relationship between IFP and metastatic propensity [54].

Conclusive studies of mechanisms linking high IFP in tumors to lymph node metastasis have not been reported thus far. However, several possible mechanisms have been suggested. High tumor IFP may force interstitial fluid to flow from the tumor tissue into adjacent normal tissues [42], and this fluid flow may direct tumor cells toward peritumoral lymphatics by autologous chemotaxis [55], and may decrease the sentinel lymph node immunity to metastatic tumor cells $[56,57]$. Moreover, the interstitial fluid may transport proteolytic enzymes and chemokines that facilitate tumor cell migration by remodeling the extracellular matrix [55], and may carry lymphangiogenic factors that promote metastasis by dilating peritumoral lymphatics and inducing lymphangiogenesis [58].
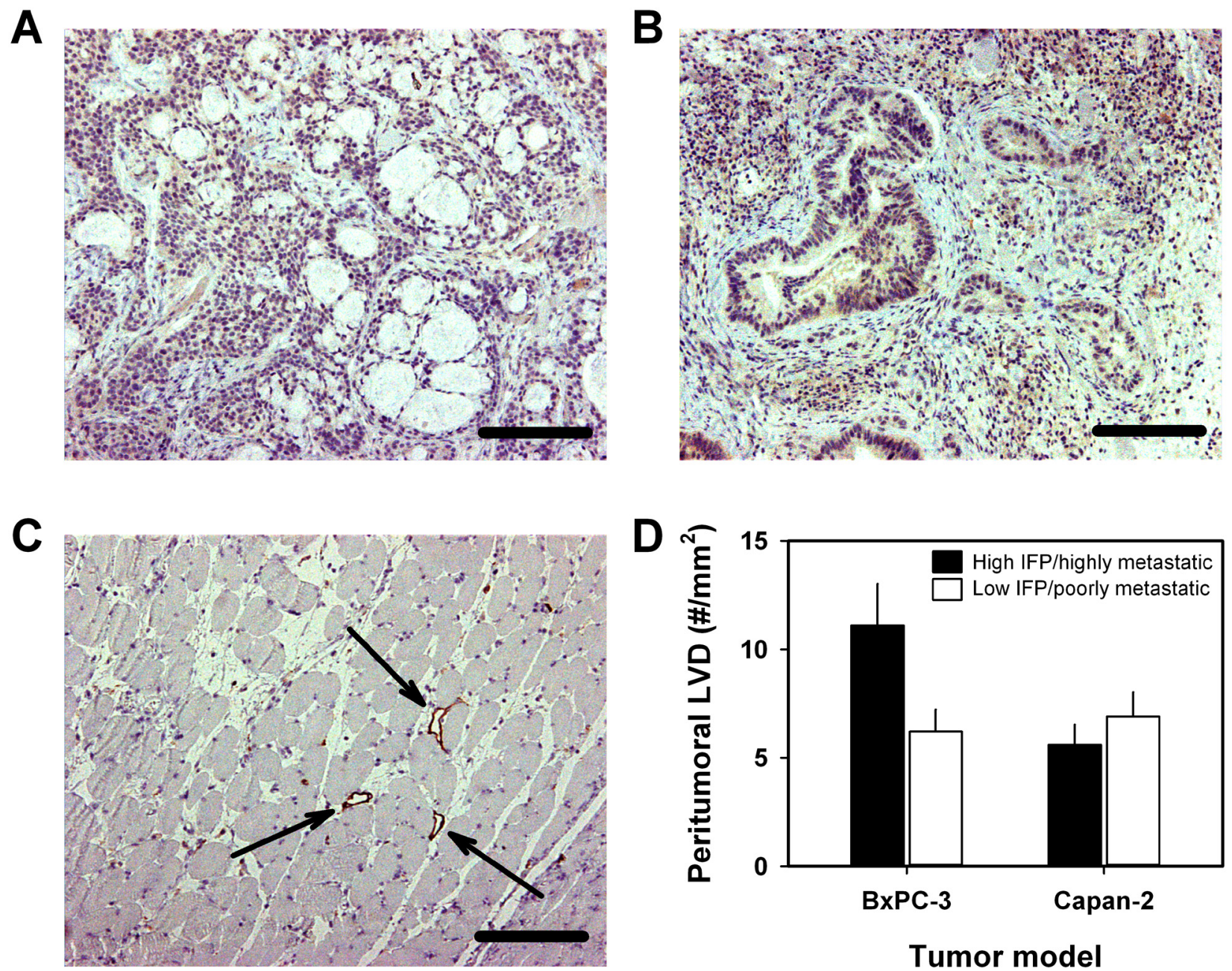

Tumor model

Figure 7: Lymphatics associated with BxPC-3 and Capan-2 PDAC xenografts. Immunohistochemical preparations stained for lymphatics by using an antibody against the endothelial cell marker LYVE-1. (A) BxPC-3 tumor showing no intratumoral lymphatics. Scale bar: $400 \mu \mathrm{m}$. (B) Capan-2 tumor showing no intratumoral lymphatics. Scale bar: $400 \mu \mathrm{m}$. (C) Peritumoral muscle tissue showing lymphatics. Arrows point to large open lymphatics. Scale bar: $400 \mu \mathrm{m}$. (D) Peritumoral lymph vessel density (LVD) of high IFP/highly metastatic and low IFP/poorly metastatic BxPC-3 and Capan-2 tumors. Columns and bars: mean values $\pm \mathrm{SD}(N=4$ tumors). 
Tumors develop elevated IFP because they show high resistance to blood flow, low resistance to transcapillary fluid flow, and impaired lymphatic drainage $[25,48]$. The resistance to blood flow is determined primarily by the density of the microvascular network and the diameter and tortuosity of the vessels. The transcapillary fluid flow is influenced strongly by the permeability of the vessel walls. The lymphatic drainage is determined by the density of the peritumoral lymphatic network and the tumor-induced dilation of the peritumoral lymphatics $[25,50]$. The IFP of tumors is thus expected to show a strong relationship to tumor-induced hem- and lymphangiogenesis.

Several proangiogenic factors associated with interstitial hypertension-associated lymph node metastasis were identified in BxPC-3 and Capan-2 tumors, and three of these factors were up-regulated in high IFP/ highly metastatic tumors in both models: TGFB, ANG, and IGF1. High expression of these genes has been shown to be associated with high incidence of lymph node metastases and poor survival rates in several cancer types [59] including PDAC [37, 38, 60]. Up-regulation of TGFB may lead to increased synthesis and cross-linking of extracellular matrix proteins, increased tumor tissue stiffness and solid stress, compression of blood vessels, collapse of intratumoral lymphatics, and highly elevated IFP [61]. Moreover, TGFB protein may promote tumor cell invasion and metastasis by facilitating epithelial-tomesenchymal transition [62]. ANG stimulates ribosomal RNA (rRNA) transcription, and ANG-mediated rRNA transcription has been revealed to be a general requirement for hem- and lymphangiogenesis induced by other angiogenic factors [63, 64]. Amplified IGF1 signaling has been shown to promote the development and progression of cancer, and furthermore, IGF1 has been identified as an important lymphangiogenic factor in several cancer types $[65,66]$. Up-regulation of lymphangiogenic factors like IGF1 may facilitate lymph node metastasis by promoting peritumoral lymphangiogenesis $[66,67]$.

In addition, high IFP/highly metastatic tumors of the BxPC-3 model showed highly increased expression of VEGF-C, and in this model, the density of peritumoral lymphatics was higher in high IFP/highly metastatic tumors than in low IFP/poorly metastatic tumors. VEGF-C is the most specific and well characterized tumor-derived lymphangiogenic factor identified thus far, and high expression of VEGF-C has been shown to facilitate lymph node and distant metastasis in numerous animal models and many malignant diseases in humans $[56,58$, $65,66]$. Our study suggests that lymph node metastasis is promoted by VEGF-C also in PDAC, and furthermore, that high expression of VEGF-C may be associated with high tumor IFP in some PDAC xenograft models. Interestingly, it has been shown that VEGF-A is up-regulated in tumors with highly elevated IFP in some xenograft models of malignant melanoma [68, 69].
Moreover, high IFP/highly metastatic Capan-2 tumors showed increased expression of TNF and members of the CXC chemokine family. TNF may promote tumor-induced lymphangiogenesis by upregulating the expression of VEGF-C and VEGF-D [70-72], and this cytokine has also been shown to facilitate lymph node metastasis by promoting epithelialto-mesenchymal transition [73]. The CXCL1, CXCL5, and CXCL6 chemokines have the ELR motif proximal to the CXC sequence, and all ELR containing CXC chemokines have been shown to be potent promoters of tumor hemangiogenesis [74]. CXCL5, which showed by far the highest up-regulation in high IFP/highly metastatic Capan-2 tumors, has been identified as an important angiogenic stimulator in experimental PDAC [75], and furthermore, overexpression of CXCL5 has been shown to be associated with poor survival in PDAC patients [76].

In summary, BxPC-3 and Capan-2 PDAC xenografts developed an abnormal microvasculature during growth, resulting in a physicochemical microenvironment characterized by hypoxia and elevated IFP. Lymph node metastasis was associated with high IFP rather than high MVD or high fraction of hypoxic tissue. Seven angiogenesis-related genes associated with high IFP-associated metastasis were identified in each of the PDAC xenograft models, and three of the genes were common for the two PDAC models. It is possible that the proteins encoded by these genes may have induced high IFP by increasing the microvascular resistance to blood flow, or may have promoted lymph node metastasis by enhancing peritumoral lymphangiogenesis or facilitating epithelial-to-mesenchymal transition. These possibilities merit to be investigated in comprehensive preclinical studies aiming at revealing causal relationships between high IFP and lymph node metastasis, studies that may lead to the identification of novel therapeutic targets for PDAC.

\section{MATERIALS AND METHODS}

\section{Tumor models}

BxPC-3 and Capan-2 (American Type Culture Collection, VA, USA) human PDAC xenografts grown in adult (8-12 weeks of age) female BALB/c nu/nu mice were used as preclinical tumor models. Tumors were initiated from cells cultured in RPMI-1640 (25 mmol/1 HEPES and l-glutamine) medium supplemented with $13 \%$ bovine calf serum, $250 \mathrm{mg} / 1$ penicillin, and 50 $\mathrm{mg} / \mathrm{l}$ streptomycin. Approximately $2.5 \times 10^{6}$ cells in 20 $30 \mu \mathrm{l}$ of Hanks' balanced salt solution were inoculated intramuscularly in the left hind leg, and tumors were included in experiments when having grown to a volume of $400-600 \mathrm{~mm}^{3}$, as measured with calipers. 


\section{Metastatic status}

Lymph node metastases were searched for by examining six pairs of lymph nodes (Figure 1). The lymph nodes were resected and their sizes were measured with a stereomicroscope before they were fixed in phosphate-buffered 4\% paraformaldehyde and prepared for histological examination. Histological sections were cut at $50-\mu \mathrm{m}$ intervals throughout the entire tissue, stained with hematoxylin and eosin, and examined for metastatic growth by light microscopy. Lungs and liver were prepared in the same way, and histological sections cut at $100-\mu \mathrm{m}$ intervals were examined for pulmonary and hepatic micrometastases. The peritoneal cavity was examined for macroscopic tumor growth.

\section{Interstitial fluid pressure}

IFP was measured with a Millar SPC 320 catheter equipped with a $2 \mathrm{~F}$ Mikro-Tip transducer (Millar Instruments, Houston, TX, USA). The catheter was connected to a computer via a Millar TC-510 control unit and a preamplifier, and data acquisition was carried out by using the LabVIEW software. The IFP of experimental tumors is relatively uniform in central tumor regions and drops steeply to normal tissue values at the tumor surface $[25,41,48]$, and therefore, IFP was measured in the tumor center in this study. Two measurements were carried out in each tumor by inserting the probe from the lateral side and then from the posterior side, and these two measurements provided highly similar values, consistent with previous studies in our laboratory [77]. Multiple measurements were not conducted because there is a danger that puncture holes may relieve the pressure so that subsequent measurements are not valid.

\section{Immunohistochemical assessment of tumor hypoxia and vascularity}

Histological sections were prepared by standard procedures and stained with hematoxylin and eosin (HE) or immunostained for hypoxia, blood vessels, or lymphatics. Pimonidazole [1-[(2-hydroxy-3-piperidinyl)propyl]-2-nitroimidazole], injected as described earlier [78], was used as a marker of tumor hypoxia, and CD31 and LYVE-1 were used as markers of blood and lymph vessel endothelial cells, respectively. An antipimonidazole rabbit polyclonal antibody (Professor James A. Raleigh, University of North Carolina, Chapel Hill, NC, USA), an anti-mouse CD31 rabbit polyclonal antibody (Abcam, Cambridge, UK), or an anti-mouse LYVE-1 rabbit polyclonal antibody (Abcam) was used as primary antibody. Quantitative studies were carried out on preparations cut through the central regions of tumors, and three sections of each staining were analyzed for each tumor. Blood vessel density was scored by counting CD31-positive vessels in whole tumor cross-sections as described elsewhere [54]. The density of peritumoral lymphatics was assessed by counting LYVE-1-positive vessels in the muscle tissue located within a distance of $0.5 \mathrm{~mm}$ from the tumor surface. Fraction of pimonidazolepositive tissue was assessed by image analysis [44] and was defined as the area fraction of the viable tissue showing positive staining.

\section{Quantitative PCR}

The $\mathrm{RT}^{2}$ Profiler PCR Array Human Angiogenesis (PAHS-024Z; SABiosciences, Frederick, MD, USA) was used for expression profiling of angiogenesis-related genes. Total RNA was isolated from tumor tissue stabilized in RNAlater RNA Stabilization Reagent (Qiagen, Hilden, Germany). RNA isolation, cDNA synthesis, and realtime PCR were carried out as described earlier [79]. Fold difference in gene expression was calculated by using the $\Delta \Delta \mathrm{C}_{\mathrm{T}}$-method [80]. $\mathrm{A}_{\mathrm{T}}$-value of 35 ( 15 cycles above the positive PCR control) was set as detection limit, and hence, all $\mathrm{C}_{\mathrm{T}}$-values above 35 were set to 35 . The arrays included five housekeeping genes $[\beta$-actin (ACTB), $\beta$-2-microglobulin (B2M), glyceraldehyde3-phosphate dehydrogenase (GAPDH), hypoxanthine phosphoribosyltransferase 1 (HPRT1), ribosomal protein lateral stalk subunit P0 (RPLP0)], and each $\mathrm{C}_{\mathrm{T}}$-value of a tumor was normalized to the mean $\mathrm{C}_{\mathrm{T}}$-value of these genes $\left(\Delta \mathrm{C}_{\mathrm{T}}=\mathrm{C}_{\mathrm{T}}\right.$ gene of interest $-\mathrm{C}_{\mathrm{T}}$ mean of housekeeping genes $)$. Normalized gene expression levels were calculated from three biological replicates as $2^{\text {-mean } \Delta \mathrm{CT}}$.

\section{Ethics}

The animal experiments were approved by the Institutional Committee on Research Animal Care and were performed in accordance with the Interdisciplinary Principles and Guidelines for the Use of Animals in Research, Marketing, and Education (New York Academy of Sciences, New York, NY, USA) and the EU Directive 2010/63/EU for animal experiments (http://ec.europa.eu/environment/chemicals/lab_animals/ legislation_en.htm).

\section{Statistical analysis}

The Pearson product moment correlation test was used to search for correlations between parameters. Curves were fitted to data by linear regression analysis. Comparisons of data were carried out by using the Student $t$ test (single comparisons) or by one-way ANOVA followed by the Bonferroni's test (multiple comparisons). The Kolmogorov-Smirnov method and the Levene's method were used to test for normality and equal variance, respectively. Probability values of $P<0.05$, determined from two-sided tests, were considered significant. The statistical analysis was carried out with SigmaStat statistical software. 


\section{CONFLICTS OF INTEREST}

The authors have no potential conflicts of interest to disclose.

\section{GRANT SUPPORT}

Financial support was received from the SouthEastern Norway Regional Health Authority and the Norwegian Cancer Society.

\section{REFERENCES}

1. Siegel RL, Miller KD, Jemal A. Cancer statistics, 2015. CA Cancer J Clin. 2015; 65: 5-29.

2. Ryan DP, Hong TS, Bardeesy N. Pancreatic adenocarcinoma. N Engl J Med. 2014; 371: 1039-1049.

3. Rahib L, Smith BD, Aizenberg R, Rosenzweig AB, Fleshman JM, Matrisian LM. Projecting cancer incidence and deaths to 2030: the unexpected burden of thyroid, liver, and pancreas cancers in the United States. Cancer Res. 2014; 74: 2913-2921.

4. Castellanos E, Berlin J, Cardin DB. Current treatment options for pancreatic carcinoma. Curr Oncol Rep. 2011; 13: 195-205.

5. Winter JM, Brennan MF, Tang LH, D'Angelica MI, Dematteo RP, Fong Y, Klimstra DS, Jarnagin WR, Allen PJ. Survival after resection of pancreatic adenocarcinoma: results from a single institution over three decades. Ann Surg Oncol. 2012; 19: 169-175.

6. Garrido-Laguna I, Hidalgo M. Pancreatic cancer: from state-of-the-art treatments to promising novel therapies. Nat Rev Clin Oncol. 2015; 12: 319-334.

7. Makohon-Moore A, Iacobuzio-Donahue CA. Pancreatic cancer biology and genetics from an evolutionary perspective. Nat Rev Cancer. 2016; 16: 553-565.

8. Fink DM, Steele MM, Hollingsworth MA. The lymphatic system and pancreatic cancer. Cancer Lett. 2016; 381: 217-236.

9. Yachida S, Iacobuzio-Donahue CA. The pathology and genetics of metastatic pancreatic cancer. Arch Pathol Lab Med. 2009; 133: 413-422.

10. Whatcott CJ, Diep CH, Jiang P, Watanabe A, LoBello J, Sima C, Hostetter G, Shepard HM, Von Hoff DD, Han H. Desmoplasia in primary tumors and metastatic lesions of pancreatic cancer. Clin Cancer Res. 2015; 21: 3561-3568.

11. Bijlsma MF, van Laarhoven HW. The conflicting roles of tumor stroma in pancreatic cancer and their contribution to the failure of clinical trials: a systematic review and critical appraisal. Cancer Metastasis Rev. 2015; 34: 97-114.

12. Feig C, Gopinathan A, Neesse A, Chan DS, Cook N, Tuveson DA. The pancreas cancer microenvironment. Clin Cancer Res. 2012; 18: 4266-4276.
13. Mahadevan D, Von Hoff DD. Tumor-stroma interactions in pancreatic ductal adenocarcinoma. Mol Cancer Ther. 2007; 6: 1189-1197.

14. Neesse A, Michl P, Frese KK, Feig C, Cook N, Jacobetz MA, Lolkema MP, Buchholz M, Olive KP, Gress TM, Tuveson DA. Stromal biology and therapy in pancreatic cancer. Gut. 2011; 60: 861-868.

15. Longo V, Brunetti O, Gnoni A, Cascinu S, Gasparini G, Lorusso V, Ribatti D, Silvestris N. Angiogenesis in pancreatic ductal adenocarcinoma: a controversial issue. Oncotarget. 2016; 7: 58649-58658. doi: 10.18632/ oncotarget.10765.

16. Craven KE, Gore J, Korc M. Overview of pre-clinical and clinical studies targeting angiogenesis in pancreatic ductal adenocarcinoma. Cancer Lett. 2016; 381: 201-210.

17. Ellis LM, Takahashi Y, Fenoglio CJ, Cleary KR, Bucana CD, Evans DB. Vessel counts and vascular endothelial growth factor expression in pancreatic adenocarcinoma. Eur J Cancer. 1998; 34: 337-340.

18. Hoem D, Straume O, Immervoll H, Akslen LA, Molven A. Vascular proliferation is associated with survival in pancreatic ductal adenocarcinoma. APMIS 2013; 121: 1037-1046.

19. Olson P, Chu GC, Perry SR, Nolan-Stevaux O, Hanahan D. Imaging guided trials of the angiogenesis inhibitor sunitinib in mouse models predict efficacy in pancreatic neuroendocrine but not ductal carcinoma. Proc Natl Acad Sci U S A. 2011; 108: E1275-E1284.

20. Olive KP, Jacobetz MA, Davidson CJ, Gopinathan A, McIntyre D, Honess D, Madhu B, Goldgraben MA, Caldwell ME, Allard D, Frese KK, Denicola G, Feig C, et al. Inhibition of Hedgehog signaling enhances delivery of chemotherapy in a mouse model of pancreatic cancer. Science. 2009; 324: 1457-1461.

21. Provenzano PP, Cuevas C, Chang AE, Goel VK, Von Hoff DD, Hingorani SR. Enzymatic targeting of the stroma ablates physical barriers to treatment of pancreatic ductal adenocarcinoma. Cancer Cell. 2012; 21: 418-429.

22. Tammi RH, Kultti A, Kosma VM, Pirinen R, Auvinen P, Tammi MI. Hyaluronan in human tumors: pathobiological and prognostic messages from cell-associated and stromal hyaluronan. Semin Cancer Biol. 2008; 18: 288-295.

23. Thompson CB, Shepard HM, O'Connor PM, Kadhim S, Jiang P, Osgood RJ, Bookbinder LH, Li X, Sugarman BJ, Connor RJ, Nadjsombati S, Frost GI. Enzymatic depletion of tumor hyaluronan induces antitumor responses in preclinical animal models. Mol Cancer Ther. 2010; 9: 3052-3064.

24. Jacobetz MA, Chan DS, Neesse A, Bapiro TE, Cook N, Frese KK, Feig C, Nakagawa T, Caldwell ME, Zecchini HI, Lolkema MP, Jiang P, Kultti A, et al. Hyaluronan impairs vascular function and drug delivery in a mouse model of pancreatic cancer. Gut. 2013; 62: 112-120. 
25. Milosevic MF, Fyles AW, Hill RP. The relationship between elevated interstitial fluid pressure and blood flow in tumors: a bioengineering analysis. Int J Radiat Oncol Biol Phys. 1999; 43: 1111-1123.

26. Horsman MR, Vaupel P. Pathophysiological basis for the formation of the tumor microenvironment. Front Oncol. 2016; 6: 66.

27. Milosevic M, Fyles A, Hedley D, Hill R. The human tumor microenvironment: invasive (needle) measurement of oxygen and interstitial fluid pressure. Semin Radiat Oncol. 2004; 14: 249-258.

28. Chauhan VP, Boucher Y, Ferrone CR, Roberge S, Martin JD, Stylianopoulos T, Bardeesy N, DePinho RA, Padera TP, Munn LL, Jain RK. Compression of pancreatic tumor blood vessels by hyaluronan is caused by solid stress and not interstitial fluid pressure. Cancer Cell 2014; 26: 14-15.

29. DuFort CC, DelGiorno KE, Carlson MA, Osgood RJ, Zhao C, Huang Z, Thompson CB, Connor RJ, Thanos CD, Scott Brockenbrough J, Provenzano PP, Frost GI, MichaelShepard H, Hingorani SR. Interstitial pressure in pancreatic ductal adenocarcinoma is dominated by a gel-fluid phase. Biophys J. 2016; 110: 2106-2119.

30. Ide T, Kitajima Y, Miyoshi A, Ohtsuka T, Mitsuno M, Ohtaka K, Miyazaki K. The hypoxic environment in tumorstromal cells accelerates pancreatic cancer progression via the activation of paracrine hepatocyte growth factor/c-Met signaling. Ann Surg Oncol. 2007; 14: 2600-2607.

31. Koong AC, Mehta VK, Le QT, Fisher GA, Terris DJ, Brown JM, Bastidas AJ, Vierra M. Pancreatic tumors show high levels of hypoxia. Int J Radiat Oncol Biol Phys. 2000; 48: 919-922.

32. Miller BW, Morton JP, Pinese M, Saturno G, Jamieson NB, McGhee E, Timpson P, Leach J, McGarry L, Shanks E, Bailey P, Chang D, Oien K, et al. Targeting the LOX/ hypoxia axis reverses many of the features that make pancreatic cancer deadly: inhibition of LOX abrogates metastasis and enhances drug efficacy. EMBO Mol Med. 2015; 7: 1063-1076.

33. Dhani NC, Serra S, Pintilie M, Schwock J, Xu J, Gallinger S, Hill RP, Hedley DW. Analysis of the intra- and intertumoral heterogeneity of hypoxia in pancreatic cancer patients receiving the nitroimidazole tracer pimonidazole. Br J Cancer. 2015; 113: 864-871.

34. Dhani N, Fyles A, Hedley D, Milosevic M. The clinical significance of hypoxia in human cancers. Semin Nucl Med. 2015; 45: 110-121.

35. Lohse I, Lourenco C, Ibrahimov E, Pintilie M, Tsao MS, Hedley DW. Assessment of hypoxia in the stroma of patient-derived pancreatic tumor xenografts. Cancers. 2014; 6: 459-471.

36. Chang Q, Jurisica I, Do T, Hedley DW. Hypoxia predicts aggressive growth and spontaneous metastasis formation from orthotopically grown primary xenografts of human pancreatic cancer. Cancer Res. 2011; 71: 3110-3120.

37. Singh D, Upadhyay G, Srivastava RK, Shankar S. Recent advances in pancreatic cancer: biology, treatment, and prevention. Biochim Biophys Acta. 2015; 1856: 13-27.

38. Fokas E, O’Neill E, Gordon-Weeks A, Mukherjee S, McKenna WG, Muschel RJ. Pancreatic ductal adenocarcinoma: from genetics to biology to radiobiology to oncoimmunology and all the way back to the clinic. Biochim Biophys Acta. 2015; 1855: 61-82.

39. Weidner N. Intratumor microvessel density as prognostic factor in cancer. Am J Pathol. 1995; 147: 9-19.

40. Vermeulen PB, Gasparini G, Fox SB, Colpaert C, Marson LP, Gion M, Beliën JA, de Waal RM, van Marck E, Magnani E, Weidner N, Harris AL, Dirix LY. Second international consensus on the methodology and criteria of evaluation of angiogenesis quantification in solid human tumours. Eur J Cancer. 2002; 38: 1564-1579.

41. Rofstad EK, Tunheim SH, Mathiesen B, Graff BA, Halsør EF, Nilsen K, Galappathi K. Pulmonary and lymph node metastasis is associated with primary tumor interstitial fluid pressure in human melanoma xenografts. Cancer Res. 2002; 62: 661-664.

42. Hompland T, Ellingsen C, Øvrebø KM, Rofstad EK. Interstitial fluid pressure and associated lymph node metastasis revealed in tumors by dynamic contrastenhanced MRI. Cancer Res. 2012; 72: 4899-4908.

43. Vaupel P, Mayer A. Hypoxia in cancer: significance and impact on clinical outcome. Cancer Metastasis Rev. 2007; 26: $225-239$

44. Rofstad EK, Galappathi K, Mathiesen B, Ruud EB. Fluctuating and diffusion-limited hypoxia in hypoxiainduced metastasis. Clin Cancer Res. 2007; 13: 1971-1978.

45. Finger EC, Giaccia AJ. Hypoxia, inflammation, and the tumor microenvironment in metastatic disease. Cancer Metastasis Rev. 2010; 29: 285-293.

46. Wegner CS, Gaustad JV, Andersen LM, Simonsen TG, Rofstad EK. Diffusion-weighted and dynamic contrastenhanced MRI of pancreatic adenocarcinoma xenografts: associations with tumor differentiation and collagen content. J Transl Med. 2016; 14: 161.

47. Grzesiak JJ, Ho JC, Moossa AR, Bouvet M. The integrinextracellular matrix axis in pancreatic cancer. Pancreas. 2007; 35: 293-301.

48. Lunt SJ, Kalliomäki TM, Brown A, Yang VX, Milosevic M, Hill RP. Interstitial fluid pressure, vascularity and metastasis in ectopic, orthotopic and spontaneous tumours. BMC Cancer. 2008; 8:2.

49. Milosevic M, Fyles A, Hedley D, Pintilie M, Levin W, Manchul L, Hill R. Interstitial fluid pressure predicts survival in patients with cervix cancer independent of 
clinical prognostic factors and tumor oxygen measurements. Cancer Res. 2001; 61: 6400-6405.

50. Boucher Y, Lee I, Jain RK. Lack of general correlation between interstitial fluid pressure and oxygen partial pressure in solid tumors. Microvasc Res. 1995; 50: 175-182.

51. Tufto I, Lyng H, Rofstad EK. Interstitial fluid pressure, perfusion rate and oxygen tension in human melanoma xenografts. Br J Cancer. 1996; 27: S252-S255.

52. Weidner N. Measuring intratumoral microvessel density. Methods Enzymol. 2008; 444: 305-323.

53. Mujcic H, Hill RP, Koritzinsky M, Wouters BG. Hypoxia signaling and the metastatic phenotype. Curr Mol Med. 2014; 14: 565-579.

54. Rofstad EK, Huang R, Galappathi K, Andersen LM, Wegner CS, Hauge A, Gaustad JV, Simonsen TG. Functional intratumoral lymphatics in patient-derived xenograft models of squamous cell carcinoma of the uterine cervix: implications for lymph node metastasis. Oncotarget. 2016; 7: 56986-56997. doi: 10.18632/oncotarget.10931.

55. Shields JD, Fleury ME, Yong C, Tomei AA, Randolph GJ, Swartz MA. Autologous chemotaxis as a mechanism of tumor cell homing to lymphatics via interstitial flow and autocrine CCR7 signaling. Cancer Cell. 2007; 11: 526-538.

56. Swartz MA, Lund AW. Lymphatic and interstitial flow in the tumour microenvironment: linking mechanobiology with immunity. Nature Rev Cancer. 2012; 12: 210-219.

57. Lund AW, Duraes FV, Hirosue S, Raghavan VR, Nembrini C, Thomas SN, Issa A, Hugues S, Swartz MA. VEGF-C promotes immune tolerance in B16 melanomas and crosspresentation of tumor antigen by lymph node lymphatics. Cell Rep. 2012; 1: 191-199.

58. Mumprecht V, Detmar M. Lymphangiogenesis and cancer metastasis. J Cell Mol Med. 2009; 13: 1405-1416.

59. Yang SY, Miah A, Pabari A, Winslet M. Growth factors and their receptors in cancer metastases. Front Biosci (Landmark Ed). 2011; 16: 521-538.

60. Keleg S, Büchler P, Ludwig R, Büchler MW, Friess H. Invasion and metastasis in pancreatic cancer. Mol Cancer. 2003; $2: 14$.

61. Jain RK, Martin JD, Stylianopoulos T. The role of mechanical forces in tumor growth and therapy. Annu Rev Biomed Eng. 2014; 16: 321-346.

62. Kalluri R, Weinberg RA. The basics of epithelialmesenchymal transition. J Clin Invest. 2009; 119: 1420-1428.

63. Kishimoto K, Liu S, Tsuji T, Olson KA, Hu GF. Endogenous angiogenin in endothelial cells is a general requirement for cell proliferation and angiogenesis. Oncogene. 2005; 24: 445-456.

64. Yoshioka N, Wang L, Kishimoto K, Tsuji T, Hu GF. A therapeutic target for prostate cancer based on angiogenin-stimulated angiogenesis and cancer cell proliferation. Proc Natl Acad Sci U S A. 2006; 103: 14519-14524.

65. Zheng W, Aspelund A, Alitalo K. Lymphangiogenic factors, mechanisms, and applications. J Clin Invest. 2014; 124: 878-887.

66. Podgrabinska S, Skobe M. Role of lymphatic vasculature in regional and distant metastases. Microvasc Res. 2014; 95: 46-52.

67. Li ZJ, Ying XJ, Chen HL, Ye PJ, Chen ZL, Li G, Jiang HF, Liu J, Zhou SZ. Insulin-like growth factor-1 induces lymphangiogenesis and facilitates lymphatic metastasis in colorectal cancer. World J Gastroenterol. 2013; 19: 7788-7794.

68. Rofstad EK, Ruud EB, Mathiesen B, Galappathi K. Associations between radiocurability and interstitial fluid pressure in human tumor xenografts without hypoxic tissue. Clin Cancer Res. 2010; 16: 936-945.

69. Rofstad EK, Galappati K, Mathiesen BS. Tumor interstitial fluid pressure-a link between tumor hypoxia, microvascular density, and lymph node metastasis. Neoplasia. 2014; 16: 586-594.

70. Du Q, Jiang L, Wang X, Wang M, She F, Chen Y. Tumor necrosis factor- $\alpha$ promotes the lymphangiogenesis of gallbladder carcinoma through nuclear factor- $\kappa \mathrm{B}$-mediated upregulation of vascular endothelial growth factor-C. Cancer Sci. 2014; 105: 1261-1271.

71. Ji H, Cao R, Yang Y, Zhang Y, Iwamoto H, Lim S, Nakamura M, Andersson P, Wang J, Sun Y, Dissing S, He $\mathrm{X}$, Yang X, Cao Y. TNFR1 mediates TNF- $\alpha$-induced tumour lymphangiogenesis and metastasis by modulating VEGF-CVEGFR3 signalling. Nat Commun. 2014; 5: 4944.

72. Hong H, Jiang L, Lin Y, He C, Zhu G, Du Q, Wang X, She F, Chen Y. TNF-alpha promotes lymphangiogenesis and lymphatic metastasis of gallbladder cancer through the ERK1/2/AP-1/VEGF-D pathway. BMC Cancer. 2016; 16: 240.

73. Chua HL, Bhat-Nakshatri P, Clare SE, Morimiya A, Badve $\mathrm{S}$, Nakshatri H. NF- $\kappa \mathrm{B}$ represses E-cadherin expression and enhances epithelial to mesenchymal transition of mammary epithelial cells: potential involvement of ZEB-1 and ZEB-2. Oncogene. 2007; 26: 711-724.

74. Keeley EC, Mehrad B, Strieter RM. CXC chemokines in cancer angiogenesis and metastases. Adv Cancer Res. 2010; 106: 91-111.

75. Wente MN, Keane MP, Burdick MD, Friess H, Büchler MW, Ceyhan GO, Reber HA, Strieter RM, Hines OJ. Blockade of the chemokine receptor CXCR2 inhibits pancreatic cancer cell-induced angiogenesis. Cancer Lett. 2006; 241: 221-227.

76. Li A, King J, Moro A, Sugi MD, Dawson DW, Kaplan J, Li G, Lu X, Strieter RM, Burdick M, Go VL, Reber HA, Eibl G, Hines OJ. Overexpression of CXCL5 is associated 
with poor survival in patients with pancreatic cancer. Am J Pathol. 2011; 178: 1340-1349.

77. Gulliksrud K, Brurberg KG, Rofstad EK. Dynamic contrast-enhanced magnetic resonance imaging of tumor interstitial fluid pressure. Radiother Oncol. 2009; 91: 107-113.

78. Rofstad EK, Rasmussen H, Galappathi K, Mathiesen B, Nilsen K, Graff BA. Hypoxia promotes lymph node metastasis in human melanoma xenografts by up-regulating the urokinase-type plasminogen activator receptor. Cancer Res. 2002; 62: 1847-1853.

79. Simonsen TG, Gaustad JV, Leinaas MN, Rofstad EK. High interstitial fluid pressure is associated with tumorline specific vascular abnormalities in human melanoma xenografts. PLoS One. 2012; 7:e40006.

80. Vanguilder HD, Vrana KE, Freeman WM. Twenty-five years of quantitative PCR for gene expression analysis. Biotechniques. 2008; 44: 619-626. 